\title{
Adam Smith e o surgimento do discurso econômico
}

\author{
Adam Smith and the genesis of the economic discourse
}

HUGO E. A. DA GAMA CERQUEIRA*,**

\begin{abstract}
RESUMO: Este artigo aborda o problema da gênese do discurso econômico. Argumenta que o trabalho de Adam Smith desempenhou um papel importante na delimitação da esfera econômica devido a: i) a natureza específica da filosofia moral de Smith; ii) a maneira como ele concebeu a economia como um domínio ontológico. No entanto, o artigo sugere que a teoria econômica de Smith permaneceu intimamente ligada à sua filosofia moral.

PALAVRAS-CHAVE: Ética e economia; discurso econômico; Adam Smith.
\end{abstract}

ABSTRACT: This article addresses the problem of the genesis of the economic dis- course. It argues that Adam Smith's work played an important role in delimiting the economic sphere because of: i) the specific nature of Smith's moral philosophy; ii) the way he conceived the economy as an ontological domain. However, the article suggests that Smith's economic theory remained closely connected to his moral philosophy.

KEYWORDS: Ethics and economies; economic discourse; Adam Smith.

JEL Classification: B12; B30; B40.

A era moderna testemunhou a emergência de uma nova maneira de considerar os fenômenos humanos e a delimitação de um domínio separado que, atualmente, evocamos através da palavra economia (economics, the economy). De que modo surgiu esta nova categoria que constitui, ao mesmo tempo, um compartimento separado no pensamento moderno e um continente confiado a uma disciplina científica e que, além disso, encarna um valor supremo do mundo moderno?

Dumont, 1977: 33

\footnotetext{
* Centro de Desenvolvimento e Planejamento Regional da Faculdade de Ciências Econômicas da Universidade de Minas Gerais - CEDEPLAR/UFMG, Belo Horizonte/MG, Brasil. E-mail: hugo@cedeplar. ufmg.br. Submetido: novembro 2002; aceito: junho 2003.

* O autor agradece a Theresa Calvet de Magalhães, João Antonio de Paula, Maurício Coutinho e Flávio Comin pelos comentários a uma versão anterior. As referências a obras de Smith seguem o sistema adotado na Glasgow edition of the works and correspondence of Adam Smith. Exceto quando ressalvado, as citações da Riqueza das nações foram tomadas da tradução de Luiz João Baraúna ("Os Economistas”, Editora Abril). Este trabalho foi realizado com o apoio do Conselho Nacional de Desenvolvimento Científico e Tecnológico (CNPq).
} 
O ponto de partida deste artigo são os trabalhos de antropólogos e historiadores — Karl Polanyi (1980; 1976), Moses Finley (1986), Marshall Sahlins (1972), Louis Dumont (1977) e outros — que chamaram a atenção para a ausência do conceito de "uma economia", do arranjo de conceitos que conformam aquilo que hoje chamamos de "economia", nas diferentes sociedades que antecederam a Modernidade, uma ausência que ainda se fazia notar em pleno século XVIII. É claro que isto não quer dizer que anteriormente não tenha existido algum tipo de reflexão sobre os assuntos que, hoje em dia, nos parecem inequivocamente econômicos: $o$ trabalho, as trocas, o dinheiro, os preços etc. $\mathrm{O}$ que não havia era a combinação destes temas em um conjunto unitário e articulado de saberes, dotado de princípios próprios. Vale dizer, não havia até o século XVIII qualquer sinal de um discurso que tratasse a esfera econômica como um conjunto de atividades compondo um sistema diferenciado no interior das sociedades.

Para os economistas habituados a pensar na história de sua disciplina tal como é ensinada nos manuais de HPE, é provável que esta afirmação desperte desconfiança. Poderiam objetar apontando a presença do discurso econômico nos escritos de mercantilistas do século XVI ou XVII. Ou poderiam apoiar suas reservas na autoridade de Schumpeter (1994: 97), para quem a "economia ganhou uma existência definida, ou até separada" nos tratados de direito e de teologia moral escritos pelos escolásticos entre os séculos XIV e XVII, “e são eles que chegam mais perto que qualquer outro grupo de terem sido os 'fundadores' da economia científica".

Estas objeções, entretanto, não resistem à crítica. Baseiam-se, sobretudo, no anacronismo - pecado capital para quem lida com a história — de atribuir aos mercantilistas e aos escolásticos um ponto de vista que não é o deles: o econômico. No que diz respeito aos mercantilistas, os conceitos que aparecem em seus trabalhos só ganham sentido se pensados do ponto de vista da organização do Estado, do corpo político. Neles, os atos de produção e distribuição material nas sociedades não são representados como ações que integram um sistema destacado da esfera da política, regido por regras próprias, ou que funcione de maneira espontânea e regular (Tribe, 1978: 35; 80-109). No mesmo sentido, Dumont (1977: 33-34) argumenta contra Schumpeter que a existência da economia como uma disciplina separada supõe não apenas a presença dos conceitos que comporão a "matériaprima" para sua reflexão - estes sim, já presentes nos tratados escolásticos mas também um modo específico de enfocar estes elementos que, para a escolástica, seguiu sendo sempre um ponto de vista não-econômico: ético.

A constatação desta ausência de um discurso econômico até o século XVIII é tão significativa que, uma vez admitida, suscita naturalmente a questão formulada por Louis Dumont no trecho que serve de epígrafe para este trabalho. Uma resposta adequada ao problema da origem da economia deve se desdobrar em, pelo menos, dois momentos. O primeiro, consiste em apontar os fatores que interditaram o surgimento de um discurso econômico nas sociedades que precederam as economias de mercado, fatores que, a nosso ver, repousam na própria estrutura daque- 
las sociedades, na maneira como as ações voltadas para assegurar sua reprodução material se orientavam por motivações extra-econômicas. Nesse sentido, as condições objetivas de possibilidade de um discurso positivo e autônomo sobre o econômico remontam ao surgimento das economias de mercado (Cerqueira, 2001).

O segundo momento da resposta à questão de Dumont deve consistir na reconstituição dos argumentos filosóficos que operaram e justificaram o surgimento de um discurso econômico não mais subordinado à ética ou à filosofia política. E é sobre este aspecto da questão que vamos nos ocupar ao longo deste artigo: nosso objetivo de fundo é compreender de que maneira o discurso econômico se constituiu, que passos a reflexão filosófica seguiu até o seu surgimento.

De acordo com o esquema proposto por Dumont (1977: 36-37), a gênese da economia requereria pelo menos duas operações. Em primeiro lugar, seria preciso mostrar a existência de uma "esfera da economia" dotada de certa coerência, apoiada em princípios ou leis distintos daqueles que fundavam a existência do Estado, princípios acessíveis à razão e que permitissem delimitar um novo campo de conhecimento. Em segundo lugar, seria necessário demonstrar que essa ordem subjacente ao domínio da vida econômica operaria espontaneamente no sentido de gerar o bem para os homens.

A primeira operação permitiria fundamentar a possibilidade de um discurso coerente e racional sobre a economia a partir de princípios extraídos do seu próprio objeto. É a descoberta de uma esfera da vida econômica, distinta da esfera política. O segundo movimento revelaria a inutilidade de qualquer regulação externa sobre a economia ao mostrar que o seu funcionamento espontâneo geraria, por si só, o bem da humanidade. Deste modo, estaria autorizada a pretensão de desvincular o discurso econômico de conceitos e orientações emanados da ética ou da filosofia política. ${ }^{1}$

Em sua tentativa de reconstituir os momentos desta trajetória que "emancipa" a economia, Dumont se depara com os trabalhos de Quesnay, Locke, Mandeville e, sobretudo, Adam Smith, cuja reflexão teria, pela primeira vez, preenchido os requisitos necessários para esta operação. Com efeito, se a paternidade da economia foi quase sempre objeto de controvérsia, poucos deixariam de reconhecer na obra de Smith um momento de inflexão no curso da história do pensamento econômico. Entretanto, existem boas razões para discordar da interpretação que Dumont nos oferece do pensamento de Smith e do papel que ele cumpre no processo de criação do discurso econômico.

O objetivo específico deste artigo é, retomando a questão e o esquema propostos por Dumont, oferecer uma interpretação alternativa da relação entre a obra de

\footnotetext{
${ }^{1} 1$ Isto equivale a dizer que a "emancipação" da economia em relação à filosofia moral não pode ser tomada em sentido estrito. Se o discurso econômico deixa de fazer referência a regras morais, isso só se justificaria pelo reconhecimento de que as ações econômicas se orientam naturalmente para o bem, ou seja, têm por si só um caráter moral.
} 
Smith e a constituição da economia como um domínio autônomo. ${ }^{2}$ Por isso mesmo, é conveniente antecipar os principais pontos que diferenciam nossa abordagem daquela proposta por Dumont, que, seguramente, é a que mais influenciou nossa compreensão do problema.

Em primeiro lugar, Dumont $(1977: 61,70)$ interpreta a autonomização da economia como o resultado de uma cisão ou oposição presentes na obra de Smith entre a "esfera geral dos sentimentos morais baseada na simpatia" e a esfera da economia, cujo funcionamento estaria apoiado apenas no egoísmo. Esta leitura se apoia em uma compreensão equivocada do conceito smithiano de simpatia, que consiste em tomá-lo como uma motivação das ações humanas e, como tal, oposto ao egoísmo ou sinônimo da benevolência. ${ }^{3} \mathrm{O}$ resultado disso é que Dumont só pode compreender aqueles trechos da Riqueza das nações que revelam os problemas decorrentes do funcionamento desimpedido da esfera econômica e apontam a necessidade da intervenção estatal para corrigi-los, como sinais de uma discrepância entre a ontologia de Smith e seu conhecimento do empírico, uma divergência entre seus princípios e sua prática (1977: 104). Ao contrário, é possível mostrar que estes problemas podem ser plenamente compreendidos à luz de sua filosofia moral. Mais importante, a consideração dos nexos que unem a ética e a economia política de Smith permite mostrar que se a "emancipação" da economia se apresenta como uma possibilidade inscrita em sua obra, ela só vai ser plenamente consumada a partir da maneira seletiva como os autores do século XIX leram e se apropriaram da Riqueza das nações. Finalmente, Dumont (1977: 88, 93) assinala a importância da "associação entre trabalho e troca" como fio condutor da obra econômica de Smith, mas busca o seu sentido numa extensa discussão das (supostas) ambigüidades da teoria do valor (1977: 61-107; 189-204). Trata-se, ao contrário, de buscar o papel deste par de conceitos não na análise econômica de Smith, mas na sua maneira de pensar o domínio ontológico da economia, no lugar que o princípio da divisão do trabalho ocupa em sua exposição e que, por sua vez, deve ser compreendido à luz da concepção metodológica que orienta sua investigação.

A próxima seção discute o argumento básico da filosofia moral de Smith, o que permitirá compreender como até mesmo aquelas ações motivadas apenas por interesses pessoais podem ser virtuosas. A seção seguinte expõe a maneira como Smith concebe as ações econômicas compondo um domínio ontológico articulado em torno de dois polos: o do trabalho e o das trocas. Finalmente, a terceira seção procura explicitar os nexos entre a filosofia moral de Smith e sua concepção da so-

\footnotetext{
${ }^{2}$ Cerqueira (2002) faz o mesmo em relação à obra de Locke e a gênese do discurso econômico.

${ }^{3} \mathrm{O}$ mesmo tipo de equívoco que levou autores alemães do século XIX a afirmarem uma contradição entre a Teoria dos sentimentos morais e a Riqueza das nações, o conhecido Adam Smith Problem. Sobre esta interpretação e as controvérsias que suscitou, ver Raphael e Macfie (1982: 20-5) e Dickey (1986), entre outros.
} 
ciabilidade mercantil e discute seu papel na criação da economia como um domínio discursivo autônomo.

\section{O PLANO DIVINO E A FILOSOFIA MORAL DE SMITH}

O projeto de Adam Smith era realizar para a filosofia moral e para os fenômenos sociais aquilo que Isaac Newton fizera no domínio da filosofia da natureza. Se o último desvelara as conexões ocultas que unem os vários fenômenos naturais, Smith pretendeu revelar os princípios que conectam e ordenam a vida em sociedade. Sua admiração pela obra de Newton não é velada e expressa-se em diferentes contextos. Ao discutir, em suas lições sobre retórica, a função de uma espécie particular de escrita que ele denomina Didática (Didactick) e que consiste na exposição de um sistema de qualquer ciência, Smith compara o método aristotélico com a maneira adotada por Newton, segundo a qual:

podemos estabelecer no início certos princípios conhecidos ou provados a partir dos quais explicamos os vários fenômenos, conectando-os todos juntos pela mesma cadeia. Esse último [método], que podemos chamar de método newtoniano, é sem dúvida o mais filosófico e em cada ciência, quer se trate da moral ou da filosofia natural etc., é imensamente mais engenhoso e, por esse motivo, mais atraente que o outro. Nos dá prazer ver os fenômenos que considerávamos os mais inexplicáveis todos deduzidos de algum princípio (normalmente um princípio bem conhecido) e todos unidos em uma cadeia... (LRBL II.133-4)

Para Newton e Smith, tais princípios refletiriam o plano (design) de um grande artífice, aquele que planejou e executou essa obra (handwork), um ser divino. Seguindo uma analogia freqüente entre os autores da Modernidade, Deus estaria para o Universo assim como o relojoeiro está para o relógio. A mão divina arranjaria e poria em movimento as peças que compõem a natureza. Para nós, os espectadores de sua obra, essa mão é invisível e apenas podemos acompanhar o resultado de seu trabalho, assim como só podemos observar o movimento dos ponteiros do relógio, mas não podemos distinguir as mãos daquele que reuniu suas peças (Evensky, 1993: 199).

Este tipo de concepção, ligada a um argumento teleológico sobre a existência de Deus, foi aplicada à filosofia moral pelos discípulos de Newton, entre os quais Lord Shaftesbury (1671-1713), Joseph Butler (1692-1752), Lord Kames (16961782) e Francis Hutcheson (1694-1746). É através de suas obras — mas também por influência do jusnaturalismo e da filosofia estóica, com suas idéias sobre uma harmonia universal - que Smith formula o projeto de expor a cadeia invisível que liga as ações humanas e conduz a sociedade ao melhor dos mundos. Neste sentido, o plano divino é não apenas uma norma ética para a qual tendem as sociedades, 
mas também um padrão analítico em relação ao qual o estágio evolutivo de cada sociedade pode ser avaliado (Evensky, 1989: 243-5).

Em sua Teoria dos sentimentos morais, ${ }^{4}$ Smith parte do princípio de que os homens estão dotados de um conjunto variado de sentimentos. Nossas experiências sensíveis atuam sobre eles, que, por sua vez, determinam nossas reações e comportamentos. O que importa frisar é que, para Smith, os diferentes sentimentos não são em si mesmos bons ou maus. A moralidade de uma ação é ditada apenas pela sua harmonia com o plano divino, ou seja, pelo fato de estar de acordo com as intenções da divindade. Um homem é virtuoso na medida em que combina e contrabalança seus sentimentos de modo a ser capaz de agir em conformidade com o plano divino, ou seja, agir de modo justo, prudente e benevolente:

Portanto, o amor-próprio não é necessariamente mau. Ele é um sentimento válido e útil. Apenas quando permitimos que atue com paixão desenfreada é que estamos agindo de uma maneira imprópria para a realização do plano da Providência. A benevolência, como prova do que foi dito, não é a rainha dos sentimentos. Ela é muito frágil, segundo Smith, para cumprir aquele papel e não proporciona o estímulo necessário para instigar o ardor produtivo. (Evensky, 1987: 452-3)

Com efeito, Smith reconhece que o amor-próprio (self-love) ou a busca do interesse pessoal (self-concern) são sentimentos naturais nos homens: "Sem dúvida, todo homem é por natureza recomendado, primeira e principalmente, ao cuidado de si mesmo; e como ele é mais apto ao cuidado de si mesmo que ao de alguma outra pessoa, é apropriado e correto que seja assim" (TMS II.ii.2.1). Esse "egoísmo" deve, no entanto, ser controlado, pois de outro modo ele poderia nos levar a violar os direitos dos outros homens e, conseqüentemente, a inviabilizar a convivência em sociedade.

De onde decorre essa capacidade de autodomínio? Para Smith, ao mesmo tempo que os homens são inclinados ao interesse próprio, eles também se preocupam com os outros homens, com sua felicidade ou seu sofrimento: "Por mais egoísta que se possa admitir que o homem seja, existem evidentemente alguns princípios em sua natureza que o levam a interessar-se pela sorte de outros e tornam a felicidade destes necessária para ele, apesar de não obter nada disso, a não ser o prazer de vê-la" (TMS I.i.1.1). Como não temos acesso direto aos sentimentos dos outros homens, só podemos formar uma idéia da maneira como eles se sentem imaginando como é que nos sentiríamos se estivéssemos em sua posição. Este sentimento de

\footnotetext{
${ }^{4}$ Publicado em 1759, foi o primeiro livro de Smith. Refletia, em boa medida, o conteúdo da segunda parte de suas lições sobre filosofia moral, ministradas na Universidade de Glasgow, a partir de 1752 . O livro, que valeu a seu autor uma fama considerável na Inglaterra e no continente, conheceu seis edições ao longo de sua vida, sendo que a última delas, contendo “adições e correções consideráveis", apareceu poucas semanas antes de sua morte (Raphael e Macfie, 1982).
} 
solidariedade (fellow-feeling), quer pela dor, quer pela alegria dos outros homens é o que Smith denomina de simpatia. ${ }^{5}$ Um sentimento como este é possível de ser concebido até mesmo por quem julga os homens movidos apenas pelo egoísmo, pois todo homem sente um prazer genuíno de perceber nas pessoas que o rodeiam aquele sentimento de solidariedade para consigo, da mesma maneira que se atormenta quando isso não ocorre (TMS I.i.2.1).

Porém, como sabemos que os outros homens não são capazes de sentir nossas emoções com a mesma intensidade que nós, somos levados a moderar nossos sentimentos para que os demais possam compartilhar deles e exibir sua simpatia para nós. Ou seja, somos levados a conhecer e moderar nossos sentimentos, projetando-nos no lugar dos outros para procurar compreender como eles nos percebem, de modo a tornar nossos sentimentos mais próximos dos deles: "Para Smith, a origem de nossa habilidade para controlar nossas paixões repousa nessa capacidade auto-reflexiva de enxergar nossa situação através dos olhos dos outros que estão intrinsecamente menos interessados nela" (Muller, 1995: 102).

Somos levados em nossa busca pela simpatia dos demais a moderar nossos sentimentos, inclusive o nosso egoísmo ou amor próprio, pois aprendemos a julgar nossas ações tal como elas devem parecer aos outros, ou ainda, tal como elas pareceriam a um "espectador imparcial" (impartial spectator). É através deste padrão ideal, ou ainda, do balanço entre o nosso egoísmo e o nosso desejo de que os outros simpatizem conosco, que Smith é capaz de derivar aquela virtude — herdada dos estóicos - que ocupa um lugar destacado em sua filosofia moral: o autodomínio (self command), ou seja, "aquele domínio das paixões que submete todos os movimentos da nossa natureza ao que a nossa própria dignidade e honra e a correção de nossa própria conduta requerem...” (TMS I.i.5.1).

É este mesmo autodomínio que está na base da possibilidade de manter a ordem social, prescindindo em larga medida de um controle direto do Estado, pois cada indivíduo tem em si um motivo para observar as normas de comportamento adequadas. Cada homem deriva de sua relação com o espectador imparcial aquela virtude mínima a partir da qual a vida em sociedade se torna possível, o sentido de justiça:

Todos os membros de uma sociedade humana precisam cada um do auxílio dos outros e estão, da mesma maneira, expostos a danos mútuos. A sociedade floresce e é feliz onde o auxílio necessário é fornecido reciprocamente pelo amor, gratidão, amizade e estima. (...) [Por outro lado] a sociedade pode subsistir entre homens diferentes, assim como entre diferentes comerciantes, por uma compreensão de sua utilidade, sem qualquer amor ou afeição mútuos. (...) A sociedade, entretanto, não

\footnotetext{
${ }^{5} \mathrm{O}$ conceito de simpatia é, portanto, mais amplo que — e não se confunde com — o de benevolência.
} 
pode subsistir entre aqueles que estão sempre prontos para prejudicar e lesar uns aos outros. (TMS II.ii.3.1-3)

Desse modo, a caridade (beneficence) é uma virtude superior, que consiste em promover a felicidade dos outros e que permite à sociedade florescer e ser feliz. Não se deve, no entanto, esperar que todos os homens ajam em relação aos demais com essa motivação desinteressada e nem isso é condição para que a sociedade exista. O requisito para a existência da sociedade consiste apenas na virtude da justiça: "A caridade, portanto, é menos essencial para a existência da sociedade que a justiça. A sociedade pode subsistir sem a caridade, ainda que não no estado mais satisfatório; mas o predomínio da injustiça deve destruí-la inteiramente" (TMS II.ii.3.3).

A virtude da justiça consiste naquele sentido de imparcialidade que emerge de nosso diálogo com o espectador imparcial. Ela depende, portanto, da nossa capacidade de avaliar os efeitos de nossas ações colocando-nos no lugar daqueles a quem podemos ofender:

Perturbar a felicidade dele [a de um outro homem] apenas porque ela encontra-se no caminho da nossa, tirar dele aquilo que lhe é realmente útil apenas porque pode ser tão ou mais útil para nós, ou favorecer, dessa maneira, às custas de outras pessoas, a preferência natural que cada homem tem por sua própria felicidade acima daquela de outras pessoas é aquilo com que nenhum espectador imparcial pode concordar. (TMS II.ii.2.1)

Sem a justiça - aqui concebida de modo semelhante à tradição do direito natural, como o direito de cada um ao que é seu — a sociedade não pode existir. É com base nisso que o Estado deve fazer cumprir o direito de cada indivíduo a sua vida e propriedade, punindo aqueles que violam esta regra (TMS II.ii.3.6):

$\mathrm{Na}$ corrida por riqueza, fama e honrarias, ele [o indivíduo] pode correr tão esforçadamente quanto for capaz, e empregar ao máximo cada nervo e músculo para ultrapassar todos os seus competidores. Mas se ele porventura atropela ou derruba qualquer um deles, a complacência dos espectadores termina por completo. Trata-se de uma violação do jogo limpo que eles não podem admitir. (...) Portanto, eles logo simpatizam com o ressentimento natural do prejudicado e o infrator torna-se o objeto de seu ódio e indignação. (TMS II.ii.2.1; cf. Muller, 1995: 111)

Esta breve apresentação do argumento moral de Smith deve ser suficiente para nos assegurar uma compreensão correta da maneira como ele foi capaz de fundar a reflexão econômica como uma disciplina separada da filosofia moral. Durante um longo período, prevaleceu uma interpretação de sua obra que estabeleceu um dualismo e, no limite, uma contradição entre os princípios expostos na Teoria 
dos sentimentos morais e aqueles apresentados na Riqueza das nações. Esta leitura consistia em afirmar que o primeiro livro tratava das ações humanas motivadas pela simpatia, enquanto o segundo se referia às ações baseadas no egoísmo. Em algumas dessas interpretações, os princípios eram tomados como características complementares. Em outras, foram entendidos como sinais de uma transição na obra de Smith, que - depois de travar contato com os filósofos franceses nos anos 1760 — teria abandonado uma teoria "altruísta" por uma concepção "egoísta" (ou "materialista”).

O equívoco básico destas leituras consiste em contrapor simpatia e egoísmo como motivações das ações humanas. Ora, para Smith a simpatia não é uma motivação, mas a operação por meio da qual é possível explicar nossos juízos morais. ${ }^{6}$

De outro lado, na Teoria dos sentimentos morais, Smith afirma sem hesitar que a busca do interesse pessoal é uma das motivações de nossas ações, inclusive das ações virtuosas, o que evidencia que não há qualquer contradição entre sua filosofia moral e sua teoria econômica (Raphael e Macfie, 1982: 20-25).

Isso nos deixa diante da seguinte questão: qual a relação entre a Teoria dos sentimentos morais e a Riqueza das nações? Desde logo, é preciso afirmar que o segundo livro não é contraditório com as teses do primeiro, mas representa sua continuação. ${ }^{7}$ Por outro lado, o seu escopo é menos abrangente, já que se refere essencialmente às ações econômicas, cuja motivação consiste no interesse pessoal.

É exatamente isso que permite a Smith tratar dos fenômenos econômicos a partir de um ponto de vista próprio ou específico, pois além de poderem ser descritos de maneira sistemática, eles têm uma natureza peculiar. Essa natureza consiste no fato de que as ações econômicas permitem alcançar o máximo bem-estar para a humanidade sem qualquer recurso à benevolência ou à caridade, mas deixando-se motivar apenas pelo amor-próprio (self-love) com que a Divindade dotou todos os homens: "Não é por conta da benevolência do açougueiro, do cervejeiro ou do padeiro que esperamos obter nosso jantar, mas sim da atenção que eles dedicam ao seu próprio interesse" (WN I.ii.2; trad. modificada). Vale dizer, Smith lida na Riqueza das nações com situações em que o único requisito moral consiste na virtude da justiça, situações em que o vínculo social se apóia apenas na "troca

\footnotetext{
${ }^{6} \mathrm{O}$ conceito de simpatia remonta à Antigüidade. Dos estóicos até o Renascimento, foi empregado sobretudo para se referir a uma conexão orgânica entre objetos do mundo físico, que se constituiria no fundamento da magia (Abbagnano, 1998: 901). Esse não é o sentido do conceito na filosofia moral de Smith, ainda que para ele mesmo essa idéia estivesse relacionada ao ponto de vista dos estóicos. A rigor, Smith reelabora o conceito de Hume, que definira a simpatia como o ato de compartilhar da dor ou prazer produzidos por alguma ação em uma outra pessoa. Para Smith, a simpatia refere-se ao compartilhar de qualquer sentimento. Além disso, do ponto de vista do julgamento moral, a aprovação de uma ação depende da simpatia que se estabelece com as motivações do agente, e não da simpatia pelos sentimentos da pessoa que sofre a ação (Cf. Raphael e Macfie, 1982: 7; 13).

${ }^{7}$ Ver o Advertisement à sexta edição da Teoria dos sentimentos morais.
} 
mercenária de bons serviços conforme uma avaliação acordada" (TMS II.ii.3.2; cf. Campbell e Skinner, 1981: 19).

O que é decisivo é que, perseguindo apenas seus interesses próprios e tendo assegurada uma condição mínima de justiça, as ações econômicas terminam proporcionando o bem-estar para a nação, sem que o Estado tenha que intervir diretamente sobre elas ou direcioná-las e sem que os homens tenham que contar com a generosidade e benevolência de seus semelhantes.

Analisar de que modo ações guiadas exclusivamente pelo amor próprio, seguindo o curso natural condizente com os princípios do plano divino, geram conseqüências involuntárias que produzem o bem comum é a tarefa da Riqueza das nações. É neste momento, na descrição do mecanismo econômico, na análise da interdependência dos fenômenos econômicos, que o conceito de trabalho ganha um papel decisivo.

\section{O TRABALHO E AS TROCAS}

As páginas iniciais da Riqueza das nações são eloqüentes sobre o novo papel assumido por este conceito: é o trabalho, trabalho em geral, a única fonte da riqueza de uma sociedade. De um lado, Smith se distancia das convicções mercantilistas, que supunham que a riqueza de uma nação só poderia provir de seu comércio externo (vale dizer, que a vantagem de uma nação só poderia advir da desvantagem das demais), mas também supera a visão unilateral da fisiocracia, que atribuía ao trabalho do agricultor — e só a ele — a capacidade de produzir riquezas. ${ }^{8}$

Essa inflexão já se apresenta nas primeiras linhas: "O trabalho anual de cada nação constitui o fundo que originalmente lhe fornece todos os bens necessários e os confortos materiais que consome anualmente" (WN I.1). Seguindo uma sugestão de Rubin (1979: 177), basta comparar o trecho acima com o início do Tesouro da Inglaterra (England's Treasure by Forraign Trade) $)^{9}$ para percebermos que estamos diante de uma nova maneira de abordar os fenômenos econômicos. Se para Thomas Mun "os meios ordinários para aumentar nossa riqueza e tesouro são pelo comércio exterior..." (Mun, 1954: 58), Smith, por sua vez, não busca mais a origem da riqueza no comércio, e nem cogita confundi-la com o tesouro, pois já a entende como o conjunto dos bens materiais disponíveis para o consumo. Para ele, a fonte da riqueza é o trabalho de uma nação, dividido entre os indivíduos que a compõem e que se distribuem pelos diferentes ramos de produção: trabalho em geral, sans phrase, e não apenas o trabalho aplicado na agricultura. E é sobre este par de conceitos, trabalho e troca, que Smith apoiará sua reflexão: o desejável crescimen-

\footnotetext{
${ }^{8}$ Os próximos parágrafos retomam alguns aspectos abordados em Paula et alli (2000).

${ }^{9}$ Escrito por Thomas Mun em torno de 1630, mas publicado apenas em 1664, trata-se do manifesto mais representativo do mercantilismo.
} 
to da riqueza é, antes de tudo, o resultado da divisão do trabalho, que deriva da propensão humana à troca.

Alguém poderia objetar que isso não basta para estabelecer a originalidade da abordagem de Smith. De um lado, o abandono de uma perspectiva estritamente monetária sobre a riqueza (tesouro), que é característica do mercantilismo, e sua identificação com as mercadorias produzidas pelo trabalho humano já poderia ser observada em trabalhos anteriores, como os de Petty (1983a: 54; 1983c: 86), Cantillon (1952: 1) e Hume (1994: 115).

No mesmo sentido, há um relativo consenso na literatura de que as proposições de Smith sobre a divisão do trabalho não contêm qualquer novidade em relação ao tratamento que seus antecessores deram ao tema. ${ }^{10}$ Petty (1683), por exemplo, já havia se referido ao fato de que a reunião de manufaturas numa grande cidade dá origem a de novos ramos de manufaturas, cada qual dividido em tantas partes quanto possível, de modo a tornar o trabalho de cada artesão mais simples e fácil e o resultado de sua produção melhor e mais barato do que se fosse feito por um único homem. Na Aritmética política, ele retorna ao assunto:

Os panos têm que ser mais baratos quando um carda, outro fia, outro tece, outro estende, outro prepara, outro passa a ferro e embrulha, do que quando todas as operações mencionadas são realizadas desajeitadamente pela mesma mão. (Petty, 1983b: 121)

Considerações semelhantes podem ser encontradas em obras deste período, como os textos de Mandeville (1924: II, 141-2), Ferguson (1995: 172-9) e Turgot (1978: 123-4). ${ }^{11}$

Nem mesmo a famosa descrição do funcionamento de uma manufatura de alfinetes, que ilustra o princípio da divisão do trabalho no primeiro capítulo da $R i$ queza das nações, tem qualquer traço de originalidade. Ao contrário do que uma leitura desatenta poderia sugerir, não se trata de um relato cuidadoso de observações empíricas feitas por Smith, já que ele mesmo afirma estar apenas retomando "um exemplo, tirado de uma manufatura muita pequena, mas na qual a divisão do trabalho tem sido muitas vezes notada" (WN I.i.3; grifo nosso).

Enfim, se não é nos conceitos de riqueza e divisão de trabalho que podemos encontrar aquilo que é original na Riqueza das nações, onde estaria a novidade capaz de tornar essa obra um divisor de águas na história do pensamento econômico? A resposta de Marx e Schumpeter é que ela reside no peso dado à divisão do

\footnotetext{
${ }^{10} 10$ Essa opinião, formulada inicialmente por Marx (1983: 275), foi adotada em seguida por autores de diferentes extrações teóricas, entre os quais Rubin (1979: 177-8), Cannan (1940) e Schumpeter (1994: 187).

1111 Cf. Rashid (1986), Campbell e Skinner (1979: 13-14) e a nota de F. B. Kay ao texto de Mandeville (1924: II, 142).
} 
trabalho. A de Rubin - que nos parece mais precisa - é que a diferença consiste no lugar ocupado pelo princípio da divisão do trabalho:

mas que feliz intuição aquela que o levou a colocar a descrição da divisão do trabalho bem no início do livro. Por conta disso, a sociedade mercantil emerge imediatamente como uma sociedade baseada, de um lado, na divisão do trabalho, e de outro, na troca entre unidades econômicas individuais - em outras palavras, como uma sociedade baseada no trabalho e na troca (uma 'sociedade comercial', para empregar o termo usado por Smith). (Rubin, 1979: 178)

Trabalho e troca formam então um par inseparável, pois é a propensão inata dos homens à troca e à barganha que dá origem à divisão do trabalho. Esta última torna-se o fio condutor da exposição, pois é a principal causa da "opulência universal". Troca e trabalho são apresentados, então, como os princípios básicos a partir dos quais a imensa variedade de fenômenos econômicos pode ser explicada (Coutinho, 1993: 110-1).

Como Dugald Stewart - o primeiro biógrafo de Smith — já notara há mais de duzentos anos, o problema de estabelecer a natureza da originalidade e o mérito de Adam Smith como fundador da economia política pode ser resumido da seguinte maneira: "o mérito de um trabalho como o do Sr. Smith deve ser avaliado não tanto pela novidade dos princípios que contém, mas pelos raciocínios empregados para sustentar estes princípios e pela maneira científica pela qual eles são expostos em sua ordem e conexão apropriadas" (Stewart, 1982: 322-3). Ordem e conexão, vale lembrar aqui, são idéias que nos remetem mais uma vez à sua intenção fundamental: fazer para os fenômenos sociais aquilo que Newton fizera para a natureza.

Ora, a divisão do trabalho ocupa, na Riqueza das nações, exatamente a posição de princípio (e princípio "bem conhecido") capaz de conectar e explicar fenômenos aparentemente desconexos e incompreensíveis (cf. Muller, 1995: 65ss.). Já no primeiro capítulo, Smith discute um paradoxo que, desde sua formulação inicial por Locke, tornou-se um lugar comum nos textos de autores do século XVIII. O problema aparece no Segundo tratado sobre o governo civil, no interior de um argumento construído para mostrar que a maior parte dos produtos que atendem às necessidades humanas deriva do trabalho e não da natureza. Para demonstrar esse ponto, Locke (1993: 297) chama a atenção para as tribos da América que dispõem de solos férteis e "contudo, por não serem melhorados pelo trabalho, não têm um centésimo das conveniências de que desfrutamos. E o rei de um território grande e fértil de lá alimenta-se, veste-se e mora pior que um trabalhador diarista na Inglaterra".

Smith reelabora o paradoxo, sem alterar sua essência. Trata-se, mais uma vez, de chamar atenção para o fato de que a condição material de um trabalhador inglês é melhor que a de um potentado de uma sociedade primitiva: 
Em comparação com o luxo extravagante dos grandes, as acomodações de um operário certamente parecem ser extremamente simples e acessíveis e, no entanto, talvez seja verdade que as acomodações de um príncipe europeu nem sempre sobrepujem a de um camponês trabalhador e frugal tanto quanto as acomodações deste último sobrepujam as de muitos reis da África, senhores absolutos das vidas e das liberdades de dez mil selvagens nus. (WN I.i.11; trad. modificada)

Fica evidente que o bem-estar material não tem relação direta com o poder de que o indivíduo dispõe. A maneira que Smith encontra para explicar este paradoxo consiste em afirmar que mesmo o trabalhador mais simples em um país civilizado dispõe de um grande número de outras pessoas trabalhando para atender suas necessidades. Assim, ele pode desfrutar da "grande multiplicação das produções de todos os diversos ofícios, em conseqüência da divisão do trabalho, que gera, em uma sociedade bem dirigida, aquela opulência universal que se estende até às camadas mais baixas do povo" (WN I.i.10; trad. modificada). Através da troca, mesmo aqueles que pertencem à classe mais baixa de uma sociedade comercial podem dispor da cooperação e do trabalho de muitas outras pessoas para prover suas necessidades, beneficiando-se dos ganhos de produtividade que a divisão do trabalho confere a cada produtor.

A demonstração desta proposição começa pela conhecida descrição da manufatura de alfinetes, com sua extensa divisão de tarefas entre dez trabalhadores, de tal modo que "um operário desenrola o arame, um outro o endireita, um terceiro o corta, um quarto faz as pontas etc." (WN I.i.3). O resultado é um enorme crescimento das forças produtivas do trabalho.

Da divisão de tarefas no interior de uma manufatura, Smith passa a outros exemplos que, desta vez, apresentam a divisão do trabalho entre produtores de diferentes ramos de produção, mostrando como até mesmo a roupa rude e simples de um trabalhador envolve em sua produção a cooperação de um sem número de produtores (WN I.i.4).

Ignorando por completo as diferenças entre os dois tipos de divisão do trabalho mencionados - a divisão técnica e a divisão social do trabalho - a atenção de Smith concentra-se no seu efeito material: o acréscimo de produtividade. Dessa maneira, ele pode apresentar a sociedade como uma imensa manufatura onde o trabalho se divide entre várias unidades separadas, mas complementares, de tal modo que a interconexão entre os produtores salta ao primeiro plano (WN I.i.11). Ainda que cada produtor esteja apenas perseguindo seu interesse individual, ele acaba, dessa maneira, atendendo ao interesse dos demais. Prevalece, portanto, a percepção de uma ordem harmoniosa entre os homens, que deixa em segundo plano os possíveis antagonismos entre os interesses individuais ou os efeitos desastrosos da concorrência sobre os produtores: disputas, falências, desemprego etc... (Rubin, 1929: 180). 
Se as vantagens da sociedade comercial derivam da divisão do trabalho, esta, por sua vez, não depende de "uma sabedoria humana qualquer, que preveria e visaria esta riqueza geral à qual dá origem”. Ao contrário ela é o resultado de uma propensão específica à natureza humana que não visa aquele fim, a tendência de satisfazer nossos interesses pessoais através da troca: "a propensão a barganhar, permutar ou trocar uma coisa pela outra" (WN I.ii.1; trad. modificada). ${ }^{12}$

É sobre essa propensão à troca que repousa a garantia do progresso na sociedade. A possibilidade de trocar os produtos do trabalho permite que cada homem dedique-se a uma única atividade e cultive seus talentos e inclinação para aquele tipo de negócio. Dessa maneira, todos se beneficiam, pois podem "comprar qualquer parcela da produção dos talentos dos outros, de acordo com suas necessidades" ao invés de terem que contar apenas com suas habilidades pessoais (WN I.ii.5).

Em resumo, o funcionamento da economia deve prescindir da benevolência (embora não se oponha a ela), até mesmo porque em uma sociedade em que cada homem depende de inúmeras outras pessoas para obter os produtos de que necessita seria impraticável conquistar a amizade de todas elas em tempo hábil. ${ }^{13}$ Além disso, um homem que dependa apenas da benevolência alheia para sua sobrevivência coloca-se em uma condição servil, ao passo que comportando-se como um comerciante, propondo aos demais algum negócio que apela apenas ao seu interesse individual — "dê-me aquilo que eu quero, e você terá isto aqui, que você quer" —, ele se comporta como um homem livre (WN I.ii.2).

A propensão à troca assegura também, através da divisão do trabalho, a máxima riqueza para a sociedade, permitindo que sejam evitadas as situações moralmente degradantes associadas à pobreza (WN I.4). Assim, Smith assegura que o funcionamento desimpedido da economia — de uma esfera da sociabilidade apoiada apenas na busca do interesse pessoal - é capaz de proporcionar as condições de liberdade e riqueza que permitem a uma sociedade alcançar a felicidade e elevar a condição moral de seus membros, afastando o fantasma da miséria ou da servidão (Muller, 1995: 70-3).

O primeiro requisito - moral - para esta demonstração foi estabelecido na Teoria dos sentimentos morais, ao diferenciar os efeitos das ações humanas dos sentimentos que as motivam. Não há, para Smith, sentimentos intrinsecamente bons ou maus. As ações guiadas por interesses estritamente pessoais, moderados pelo espectador imparcial para que não violem a regra da justiça, geram, de modo imprevisto, o bem comum, a felicidade da humanidade. O que torna um sentimento

\footnotetext{
${ }^{12}$ Cf. Polanyi (1980: 59) a propósito do equívoco histórico da afirmação de uma propensão inata à troca: "Em retrospecto, pode-se dizer que nenhuma leitura errada do passado foi tão profética do futuro." ${ }^{13}$ Mas, convém insistir, o funcionamento da economia não pode prescindir da simpatia, da qual depende a virtude básica da justiça.
} 
virtuoso é o acordo entre os resultados das ações que ele promove e o desígnio estabelecido pela Divindade ao criar o mundo (Evensky, 1987: 452-3). ${ }^{14}$

A segunda condição - ontológica - foi estabelecida nos capítulos iniciais da Riqueza das nações e consiste em apresentar a sociedade como um conjunto de pessoas que trabalham e que trocam. Pela divisão do trabalho, cada homem participa de um processo produtivo que o mantém em conexão com os demais, pois "são muito poucas as necessidades que o homem consegue atender com o produto de seu próprio trabalho. A maior parte delas deverá ser atendida com o produto do trabalho de outros..." (WN I.v.1). Para tanto, além de trabalharem, os homens precisam trocar: "Assim sendo, todo homem subsiste por meio da troca, tornando-se de certo modo comerciante; e assim é que a própria sociedade se transforma naquilo que é propriamente uma sociedade comercial" (WN I.iv.1; trad. modificada). Ao trocarem os produtos de seus trabalhos, os homens estarão obtendo o trabalho de outros. E como a divisão do trabalho é limitada pelo tamanho do mercado, quanto mais se generalizem as trocas, maior será a opulência proporcionada pelo trabalho.

Esta descrição da esfera econômica revela, em primeiro lugar, que o que parece ser uma troca de produtos por dinheiro consiste numa troca de produtos do trabalho humano e, em segundo lugar, que a troca de produtos do trabalho de diferentes produtores se reduz, na verdade, a uma troca de trabalhos (Rubin, 1979: 182).

É essa ontologia da economia que fundamenta a possibilidade de analisar os fenômenos de um ponto de vista teórico e estritamente econômico. Smith pretendeu mostrar não apenas que a esfera da economia obedecia a princípios distintos daqueles que prevalecem na esfera política - e que serão o objeto dos dois primeiros livros da Riqueza das nações - como também que a ordem subjacente ao domínio da vida econômica operaria espontaneamente no sentido de gerar o bem da humanidade, permitindo assim que o discurso econômico se "emancipasse" da filosofia moral. Convém, no entanto, frisar que essa "emancipação" deve ser entendida cum grano salis: a reflexão sobre a economia só ganha autonomia teórica porque seu objeto (as ações econômicas) é apresentado até aqui como algo que está naturalmente orientado para o bem, algo que tem, por si só, um caráter moral.

É só depois de ter desenhado a sociedade como uma sociedade de homens que trabalham e trocam - só depois de haver situado as trocas no interior de uma ontologia da sociedade mercantil — que Smith procurará explicar os determinantes das proporções segundo as quais trocas se realizam (Coutinho, 1993: 111). É pre-

\footnotetext{
14 “A felicidade da humanidade, bem como de todas as outras criaturas racionais, parece ter sido o propósito original projetado pelo Autor da natureza, quando ele as trouxe à existência. (...) E essa opinião (...) é ainda mais confirmada pelo exame dos trabalhos da natureza, que parecem todos projetados para promover a felicidade e proteger contra a miséria. Mas, agindo de acordo com os ditames de nossas faculdades morais, perseguimos necessariamente os meios mais eficazes para promover a felicidade da humanidade e pode-se dizer, portanto, que, em certo sentido, cooperamos com a Divindade e promovemos, tanto quanto está em nosso poder, o plano da Providência.” (TMS III., v. 7)
} 
cisamente por ver nas trocas um mecanismo de coordenação entre os diferentes ramos de produção que a teoria do valor pode assumir a centralidade que ela tem em sua teoria econômica - diga-se de passagem, precisamente o que faltava aos fisiocratas e à maioria dos antecessores de Smith.

Deste ponto em diante, o que estará em jogo é propriamente a análise econômica, um problema que escapa ao escopo deste ensaio. Interessa-nos apenas, antes de concluir, salientar alguns aspectos adicionais da relação entre a filosofia moral e a economia política de Smith. Trata-se de pôr em questão até que ponto a possibilidade de "emancipar" o discurso econômico é levada a termo em sua obra.

\section{ÉTICA E ECONOMIA}

Até aqui, enfatizamos o fato de que, para Smith, o funcionamento desimpedido da "sociedade comercial" não depende de que cada homem seja benevolente, mas, ao contrário, permite que eles usufruam um nível de riqueza e bem-estar que torna possível que cada um exercite a benevolência, ao mesmo tempo em que elimina o risco das situações moralmente degradantes associadas à pobreza.

Este potencial, no entanto, é colocado em risco pelos efeitos negativos do próprio desenvolvimento das "sociedades comerciais", que reclamam a atenção e o cuidado do legislador. O governo é chamado não apenas a prover a defesa, justiça e infra-estrutura, que são condições necessárias para o desenvolvimento do mercado, mas também a tomar medidas que se contraponham aos efeitos debilitantes da divisão do trabalho sobre a capacidade moral dos trabalhadores (Muller, 1995: 148-50).

É o próprio Smith quem reconhece os riscos envolvidos na divisão do trabalho. Numa passagem do livro V da Riqueza das nações, ele comenta os efeitos degradantes da especialização sobre as habilidades intelectuais e a faculdade de exercer juízos morais dos trabalhadores especializados:

Com o avanço da divisão do trabalho, a ocupação da maior parte daqueles que vivem do trabalho, isto é, da maioria da população, acaba restringindo-se a algumas ocupações extremamente simples, muitas vezes a uma ou duas. Ora, a compreensão da maior parte das pessoas é formada pelas suas ocupações normais. O homem que gasta toda sua vida executando algumas operações simples, cujos efeitos também são, talvez, sempre os mesmos ou mais ou menos os mesmos, não têm nenhuma oportunidade para exercitar sua compreensão ou para exercer seu espírito inventivo no sentido de encontrar meios para eliminar dificuldades que nunca ocorrem. Ele perde naturalmente o hábito de fazer isso, tornando-se geralmente tão embotado e ignorante quanto o possa ser uma criatura humana. $\mathrm{O}$ entorpecimento de sua mente o torna não somente incapaz de saborear ou ter alguma participação em toda con- 
versação racional, mas também de conceber algum sentimento generoso, nobre ou terno, e, conseqüentemente, de formar algum juízo justo até mesmo acerca de muitas das obrigações normais da vida privada. (...) Assim, a habilidade que ele adquiriu em sua ocupação específica parece ter sido adquirida à custa de suas virtudes intelectuais, sociais e marciais. Ora, em toda sociedade evoluída e civilizada, este é o estado em que inevitavelmente caem os trabalhadores pobres — isto é, a grande massa da população - a menos que o Governo tome algumas providências para impedir que tal aconteça. (WN V.i.f.50)

No juízo de Smith, os riscos que decorrem desta degeneração dos indivíduos não superam os benefícios que a mesma divisão do trabalho proporciona para a sociedade. No entanto, fica aí relativizada a idéia de que o livre funcionamento do domínio econômico permite à humanidade alcançar a felicidade. Afinal, a capacidade do indivíduo de executar juízos morais e, desse modo, aderir às virtudes da prudência e da justiça é uma condição para a própria preservação da sociedade comercial. A preservação desta capacidade passa a depender da mão visível do Estado, do apelo à liderança moral do governante. Deste modo, a filosofia moral continua ocupando uma posição central no pensamento econômico de Smith.

Se a idéia de um "sistema de liberdade natural" consiste, efetivamente, no eixo em torno do qual se organiza a exposição do sistema econômico na Riqueza das nações, ${ }^{15}$ ela está referida neste texto à concepção mais geral que Smith apresenta sobre a natureza do processo civilizatório. Ela consiste em afirmar que a liberdade para que cada indivíduo busque seu interesse próprio não se contrapõe ao bem comum ou ao desenvolvimento da civilização. Neste sentido, Smith tenta conciliar o desenvolvimento do comércio com as virtudes cívicas e rompe com a visão predominante em sua época sobre uma oposição incontornável entre o impulso aquisitivo, próprio das economias mercantis, e os valores morais. Uma mão invisível concilia a busca do interesse individual com a manutenção da ordem e coesão social (Tribe, 1995:25-8).

Porém, estas e outras considerações apresentadas nos livros IV e V da Rique$z a$ das nações, que problematizam as relações entre riqueza e virtude no desenvolvimento da civilização, foram, em grande medida, ignoradas ou obscurecidas na recepção dessa obra pelos economistas da primeira metade do século XIX. Na Inglaterra, as críticas aos efeitos da divisão do trabalho continuaram a ser formuladas, porém por autores que se situavam fora da economia política - quando não

\footnotetext{
15 “Conseqüentemente, uma vez eliminados inteiramente todos os sistemas, sejam eles preferenciais ou de restrições, impõe-se por si mesmo o sistema óbvio e simples da liberdade natural. Deixa-se a cada qual, enquanto não violar as leis da justiça, perfeita liberdade de ir em busca de seu próprio interesse, a seu próprio modo, e fazer com que tanto seu trabalho como seu capital concorram como os de qualquer outra pessoa ou categoria de pessoas.” (WN IV.ix.51)
} 
opostos a ela -, tais como Coleridge ou Carlyle (Copley, 1995:17-8). Ao contrário, autores como Ricardo e Malthus, a partir de uma leitura da Riqueza das nações centrada essencialmente nos dois livros iniciais e na exposição do "sistema de liberdade natural", consolidaram a imagem de Adam Smith como o criador de uma nova ciência, a economia política (Tribe, 1995:24).

$\mathrm{Na}$ segunda metade do século XIX, estas referências mais amplas do sistema de liberdade natural foram gradualmente esquecidas e a lição de Smith foi reduzida a uma mera defesa do livre comércio. Despida de suas intenções originais, a $R i$ queza das nações passou a ser lida apenas como uma descrição do funcionamento auto-regulado e espontâneo do mercado, uma análise da produção e distribuição das riquezas materiais articuladas exclusivamente em torno de uma teoria do valor (de troca). As relações entre ética, economia e política foram, então, deslocadas para um plano secundário ou esquecidas.16

\section{NOTAS CONCLUSIVAS}

O trajeto percorrido até aqui procurou explicitar de que modo foi possível fundar na Modernidade um discurso econômico cuja auto-imagem é a de um saber positivo, autônomo em relação à ética. Procurou-se mostrar de que maneira a $R i$ queza das nações se constituiu num ponto de inflexão crucial neste processo. Smith logrou conciliar a busca da vantagem pessoal, característica das "sociedades comerciais", com o objetivo prático-moral — inscrito no plano da Providência — de alcançar o bem da humanidade. Empregando a metáfora da mão invisível, a $R i$ queza das nações nos revela como uma sociabilidade apoiada na divisão do trabalho e nas trocas e movida pelo princípio da barganha produz como resultados inesperados a "opulência universal". Ela demonstraria, portanto, a existência de um domínio especificamente econômico, dotado de coerência interna e, sobretudo, que operaria espontaneamente no sentido de gerar o bem da humanidade.

Essa ontologia do sistema de livre mercado constitui o principal legado de Smith para a constituição do discurso econômico: a imagem de uma esfera da economia movida pelo interesse pessoal, que produz resultados superiores aos alcançados por qualquer forma alternativa de organização da produção material. No entanto, as ligações complexas entre essa concepção e a filosofia moral que a fundamenta - nexos que eram evidentes na obra de Smith e que o levaram a apontar os problemas decorrentes do próprio funcionamento do mercado e a relativizar suas virtudes - foram gradualmente esquecidos à medida que a economia política se desenvolveu, ao longo do século XIX. Elevada à condição de cânone da nova ciência, a Riqueza das nações passou a ser lida como um texto desvinculado ou, até mesmo, contraditório com a filosofia moral à qual estava referida. A centralidade da ética no projeto de Smith tornou-se, no discurso econômico, uma dimensão anulada. 
Deste modo, o nome de Adam Smith permaneceu associado não apenas à imagem do fundador da ciência econômica, mas também a um modo específico de conceber essa disciplina, qual seja, como uma afirmação das virtudes do laissez-faire. Estudos mais recentes sobre a obra de Smith têm contribuído para perceber o que há de caricatural nessa imagem. Deixando em segundo plano as análises econômicas para enfocarem a dimensão política e ética de seu pensamento, ao mesmo tempo em que se preocupam em localizá-lo em relação aos problemas e motivações intelectuais do século XVIII, tais pesquisas trouxeram à luz um quadro totalmente diverso, mais matizado e complexo, do qual emerge um Smith mais cético ou menos entusiasmado com os benefícios derivados da criação das sociedades comerciais (cf. Brown, 1997; Tribe, 1999).

Se a liberdade de perseguir os interesses próprios, que é característica das sociedades comerciais, está vinculada na obra de Smith a uma ordem moral que liga cada indivíduo à sociedade, a consideração destes pressupostos morais deveria nos levar a uma revisão da compreensão tradicional dos objetivos, natureza e limites de sua teoria econômica. Para além do interesse que a compreensão do pensamento de Smith tem em si mesma, não é ocioso apontar a relevância e a atualidade que alguns desdobramentos dessa investigação podem ter. A reconstrução dos argumentos de Smith, de sua linguagem e contexto, pode contribuir para nos proporcionar um novo entendimento das relações entre a ética e economia, esforço que vem sendo reclamado por filósofos e economistas.

Tal como afirma Amartya Sen (1999), a teoria econômica empobreceu sensivelmente sua abordagem ao ignorar a variedade das considerações morais que determinam os comportamentos humanos, inclusive os econômicos, e centrar-se exclusivamente nas motivações ditadas pelo interesse pessoal. Em particular, acabou assumindo uma concepção de racionalidade restrita, que iguala o comportamento racional à busca do interesse individual e considera irracionais quaisquer comportamentos guiados por outras motivações. A exemplo de Sen, cremos que existem poucos indícios de que Smith realmente tivesse a visão parcial e limitada sobre as motivações morais dos atos econômicos que se costuma atribuir a ele e que ainda caracteriza a teoria econômica moderna, e que "vale a pena discutir essa questão porque Smith foi figura de máxima importância na origem da economia e também porque o tratamento que ele deu ao tema é verdadeiramente esclarecedor e útil” (Sen, 1999: 37-8).

\section{REFERÊNCIAS BIBLIOGRÁFICAS}

ABBAGNANO, Nicola. Dicionário de filosofia, trad. de Alfredo Bosi, São Paulo: Martins Fontes, 1998. BROWN, Vivienne. 'Mere inventions of the imagination': a survey of recent literature on Adam Smith. Economics and philosophy, v. 13(2): 281-312, 1997.

CAMPBELL, Roy H. e SKINNER, Andrew. "General introduction". In: SMITH, Adam. An inquiry 
into the nature and causes of the wealth of nations. Eds. R. H. Campbell, A. S. Skinner e W. B. Todd. Indianapolis: Liberty Fund, 1981, pp. 1-60.

CANTILLON, Richard. Essai sur la nature du commerce en général. Paris: INED, 1952. CERQUEIRA, Hugo E. A. G. "O discurso econômico e suas condições de possibilidade”. Síntese - revista de filosofia, v. 28(3): 391-405, 2001.

"Trabalho e política: Locke e o discurso econômico". Revista de economia política, v.

22(1): 150-169, 2002.

"Para ler Adam Smith: novas abordagens". (Texto para discussão n 183), Belo Horizonte: Cedeplar-UFMG, 2003.

COPLEY, Stephen. "Introduction: reading the Wealth of Nations". In: COPLEY, Stephen e SUTHERLAND, Kathryn (eds.). Adam Smith's Wealth of Nations: new interdisciplinary essays. Manchester: Manchester Univ. Press, 1995, pp. 1-22.

COUTINHO, Maurício C. Lições de economia política clássica. São Paulo: Hucitec, 1993. DUMONT, Louis. From Mandeville to Marx: the genesis and triumph of economic ideology. Chicago: Univ. of Chicago Press, 1977.

EVENSKY, Jerry. "The two voices of Adam Smith: moral philosopher and social critic". History of political economy, v. 19(3): 447-68, 1987.

"The evolution of Adam Smith's views on political economy". History of political economy, v. 21(1): 123-45, 1989.

"Ethics and the invisible hand". Journal of economic perspectives, v. 7(2): 197-205, 1993. FERGUSON, Adam. An essay on the history of civil society. Cambridge: Cambridge Univ. Press, 1995. FINLEY, Moses. A economia antiga, trad. de Luísa Feijó e Carlos Leite, Porto: Afrontamento, 1986. HUME, David. Political essays, Cambridge: Cambridge Univ. Press, 1994.

LOCKE, John. Two treatises of government. Ed. Peter Laslett. Cambridge: Cambridge Univ. Press, 1993. MANDEVILLE, Bernard. The fable of the bees, or private vices, publick benefits. Indianapolis: Liberty Fund, 1988 [reimpressão em fac-símile da edição de F. B. Kaye. Oxford: Clarendon Press, 1924]. MULLER, Jerry Z. Adam Smith in his time and ours: designing the decent society, Princeton: Princeton Univ. Press, 1995.

MUN, Thomas. La riqueza de Inglaterra por el comercio exterior. Trad. esp., México: Fondo de Cultura Económica, 1954.

MURPHY, James B. The moral economy of labor. New Haven: Yale Univ. Press, 1993.

PAULA, João A., CERQUEIRA, Hugo E. A. G. e ALBUQUERQUE, Eduardo M. "Trabalho e conhecimento: lições de clássicos para a análise do capitalismo contemporâneo”. Estudos econômicos, v 30(3): 419-446, 2000.

PETTY, William. "Another essay in political arithmetick, concerning the growth of the city of London", 1683 [apud CAMPBELL e SKINNER (1979:13)].

"Tratado dos impostos e contribuições". In: . Obras econômicas. Trad. de Luis Henrique L. Santos, São Paulo: Abril Cultural, 1983a, pp. 3-78. "Aritmética política". In: Obras econômicas. Trad. de Paulo de Almeida, São Paulo: Abril Cultural, 1983b, pp. 103-158. "Verbum sapienti". In: Obras econômicas. Trad. de Paulo de Almeida, São Paulo: Abril Cultural, 1983c, pp. 79-102.

POLANYI, Karl. "La economía como actividad institucionalizada”. In: POLANYI, Karl, ARENSBERG, Conrad M. e PEARSON, Harry W. (org.). Comercio y mercado en los imperios antiguos. Trad. de Alberto Nicolás, Barcelona: Editorial Labor, 1976b, pp. 289-316 A Grande transformação: as origens da nossa época. Trad. de Fanny Wrobel, Rio de Janeiro: Campus, 1980. 
RAPHAEL, David D. e MACFIE, Alec L. "Introduction". In: SMITH, Adam. The theory of moral sentiments. Eds. D. D. Raphael e A. L. Macfie. Indianapolis: Liberty Fund, 1982, pp. 1-52.

RASHID, Salim. "Adam Smith and the division of labour: a historical view". Scottish journal of political economy, v. 33, n. 3: 292-297, 1986.

RUBIN, Isaac I. A history of economic thought. Trad. de Donald Filtzer, London: Ink Links, 1979. SAHLINS, Marshall. The stone age economics. New York: Aldine, 1972.

SCHUMPETER, Joseph A. History of economic analysis. London: Routledge, 1994.

SEN, Amartya. Sobre ética e economia. Trad. de Laura Motta, São Paulo: Companhia das Letras, 1999. SKINNER, Andrew. "Early writings: science and the role of imagination". In: SKINNER, A system of

social science. Oxford: Clarendon Press, 1986, pp. 25-47.

SMITH, Adam. An inquiry into the nature and causes of the wealth of nations. Eds. R. H. Campbell, A. S. Skinner e W. B. Todd. Indianapolis: Liberty Fund, 1981. Trad. de Luiz João Baraúna: A riqueza das nações: investigação sobre sua natureza e suas causas. São Paulo (Col. "Os economistas"): Abril Cultural, 1983.

The theory of moral sentiments. Eds. D. D. Raphael e A. L. Macfie. Indianapolis: Liberty Fund, 1982a.

Lectures on rhetoric and belles lettres. Ed. J. C. Bryce. Indianapolis: Liberty Fund, 1985. STEWART, Dugald. "Account of the life and writings of Adam Smith”, LL.D. In: SMITH, Adam. Essays on philosophical subjects. Ed. W. P. D. Wightman. Indianapolis: Liberty Fund, 1982, pp. 269-351.

TRIBE, Keith. Land, labour and economic discourse. London: Routledge and Kegan Paul, 1978.

"Natural liberty and laissez-faire: how Adam Smith became a free trade ideologue". In: COPLEY, Stephen e SUTHERLAND, Kathryn (eds.). Adam Smith's Wealth of Nations: new interdisciplinary essays. Manchester: Manchester Univ. Press, 1995, pp. 23-44.

“Adam Smith: critical theorist?”. Journal of economic literature, v. 37(2): 609-632, 1999. TURGOT, Anne-Robert-Jacques. Reflexões acerca da formação e distribuição das riquezas. Trad. de Edson Bini, São Paulo: Global, 1978. 